\title{
基本高水流量の確率特性に関する研究 STUDY ON THE PROBABILITY CHARACTERISTICS OF DESIGN FLOOD DISCHARGE
}

\author{
岡田 耕 1 ・栗田 秀明 2 ・西岡 昌秋 $3 \cdot$ 端野 道夫 4 ・神田 徹 5 \\ Tsutomu OKADA, Hideaki KURITA, Masaaki NISHIOKA, Michio HASHINO and Tohru KANDA
}

\author{
1 フェロー 工修㧣建設技術研究所 管理本部 (\% 103-8430 東京都中央区日本橋本町 4-9-11) \\ 2 正会員 工博 侏建設技術研究所 広島支店技術部（广 730-0013 広島市中区八丁堀 2-31） \\ 3 正会員 工修侏建設技術研究所 大阪支社水・計画部 (广 540-0008 大阪市中央区大手前 1-2-15) \\ 4 フェロー 工博 徳島大学教授 工学部建設工学科 ( $\% 770-8506$ 徳島市南常三島町 2-1) \\ 5 正会員 工博 神戸大学教授 工学部建設学科(广 657-8501 神戸市灌区六甲台町)
}

\begin{abstract}
In river planning, a design flood discharge has been decided based on runoff analyses of design storm hyetographs with a given return period. However, the design return period of the design flood discharge seldom coincides with that estimated statistically based on data of observed flood discharges. In this paper, the difference between the probabilities of the design flood discharges and design storm rainfalls is evaluated using a bi-variate probability theory.
\end{abstract}

Key Words: River Planning, Design Flood Discharge, Return Period, Confidence Interval, Stochastic Analysis

1.はじめに

洪水防御計画は, 計画基準点において計画の基本 となる洪水のハイドログラフ(基本高水)を設定す る。基本高水は, 洪水の生起確率によって評価され, それが治水安全度を表す。

一方, 通常の一級河川においては, 所定の治水安 全度に対応する超過確率を持つ計画降雨を定め, こ の計画降雨からハイドログラフを設定する方法を標 準としている。

しかし,この方法では, 計画降雨量について平均 して何年に一度の割合でその值を超過するかを示し ており, 洪水のピーク流量の年超過確率とは必ずし も 1：1に対応しない。

河川砂防技術基準 (案) 同解説 計画編 ”によれ ぱ, 洪水防御計画においては, 河川の氾濫する確率, すなわち基本高水のピーク流量 (以後, 基本高水流 量し呼ぶ)の超過確率が重要乞なるので，この值し 計画降雨量の年超過確率との間に著しい差異が生ず るおそれがある場合には,これらの関係を明確にし， 他の手法によって計画の規模を定めることを検討す る必要がある, とされている。
本研究では, 従来の方法により推定されている基 本高水流量の超過確率と計画降雨量の超過確率との 差異を二変数確率理論により評価することを試み た。

\section{2. 研究の概要}

\section{（1）降雨量の変動域}

治水計画においては，ある確率年に対応する計画 水文量を推定することが必要となる。その際には, 実測值の経験分布を確率紙上にプロットし，これと 適合度の良い確率分布を理論的に求め推定する。こ のとき, 抽出された標本が変化した場合には, 確率 水文量が変化することになる。

統計学において, このような変動の幅を変動域と 呼ぶ。変動域は, $\mathrm{T}$ 年確率水文量を平均値とする正 規分布と仮定したときの標準偏差で表す。これは, 確率分布形の母数を最光法により推定するときの, 推定誤差の分散共分散行列を用いて推定する。

端野 ${ }^{21}$ は, 河川計画の分野において確率水文量の 推定手法として一般的な, 3 母数の対数正規分布に ついて, 最尤法による母数推定法を示すとともに, 
母数推定値の信頼限界への適用を図っている。

本研究では.,この考え方を治水計画において基木 量となる流量および降雨量の統計解析に適用して, それぞれの変動域を推定した。

なお， 2 母数の分布形で代表的な Gumbel 分布に ついても, 別途同様の検討を行った。従来の治水計 画においては，プロッティングポジションとの適合 度の最も良い分布形を採用する場合がほとんどであ る。このため本研究では, 確率分布形の採用基準と して, 適合度を重視し，3 母数対数正規分布を採用 することとした。

\section{（2）基本高水流量の信頼確率}

基本高水流量は，いくつかの実績降雨波形を計画 降雨量まで引き伸ばし, 流出解析を行って算定して いる。このとき, 降雨量が同じであっても, 降雨波 形の時間分布・地域分布がそれぞれに異なるため, 選定した降雨波形の数だけピーク流量が得られるこ とになる。実際には, これらのピーク流量群から， カバー率の検討を行った後に決定されている。

図-1 はリターンピリオド $\mathrm{T}$ 年における平面を表 している。横軸には降雨量 $\mathrm{R}$ の基準化変数 $\mathrm{y}$ をと り,縦軸にはピーク流量 $\mathrm{Q}_{\mathrm{p}}$ の基準化変数 $\mathrm{x}$ をとる。 $\mathrm{y}$ 軸上の正規分布 $\mathrm{f}(\mathrm{y})$ は，（1)で述べたリターンピリ オド $\mathrm{T}$ 年における最尤推定量を平均值, 変動域を 標準偏差にもつ確率分布を表す(降雨量の確率分布 自身を表しているのではない)。条件付き確率分布 $\mathrm{f}(\mathrm{x} \mid \mathrm{y})$ は, リターンピリオド $\mathrm{T}$ 年規模の降雨量を持 つ, いくつかの降雨波形から得られるピーク流量群 の確率分布を表している。

一方, この平面上における, $\mathrm{x}, \mathrm{y}$ の同時超過確率 $\mathrm{H}(\mathrm{x} \cdot, \mathrm{y} \cdot)$ は, リターンピリオド $\mathrm{T}$ 年の降雨量 $\mathrm{y} \cdot$ と, その降雨量を持つ洪水波形が生起させるピーク流量 x·とを同時に超過する確率を表している（図-2 参 照)。この $\mathrm{H}(\mathrm{x} \cdot, \mathrm{y} \cdot)$ により, 従来の方法により求め られた基本高水流量の超過確率と計画降雨量の超過 確率との差異を評価する。本研究では, この超過確 率 $\mathrm{H}(\mathrm{x} \cdot, \mathrm{y} \cdot)$ を基本高水流量の信頼確率と表現する こととする。

\section{3.統計解析手法}

\section{（1）対数正規分布の変動域}

3 母数対数正規分布は次の式で表される。

$$
\left\{\begin{array}{l}
F(y)=\int_{-\infty}^{x} \frac{1}{\sqrt{2 \pi}} \exp \left(\frac{-y^{2}}{2}\right) d y \\
y=k \ln \left\{\frac{x+b}{c}\right\}, \quad-b<x<\infty
\end{array}\right.
$$

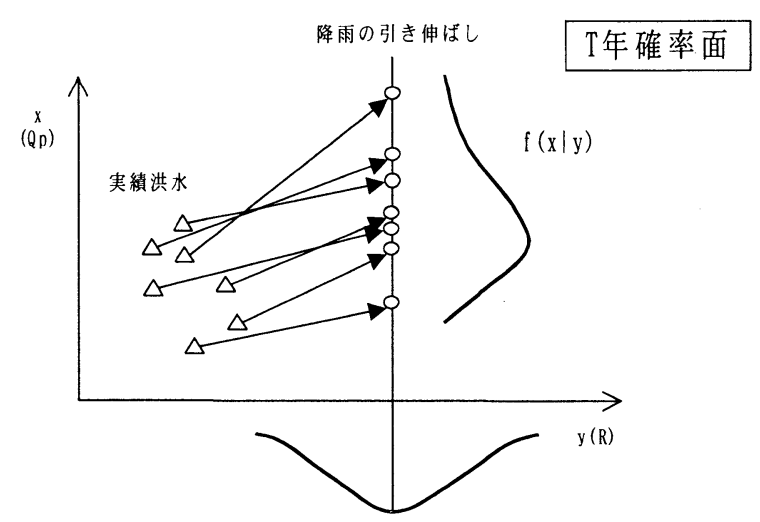

$f(y):$ 正規分布

図-1 $\mathrm{T}$ 年確率平面上の計画降雨と基本高水流量群 との関係

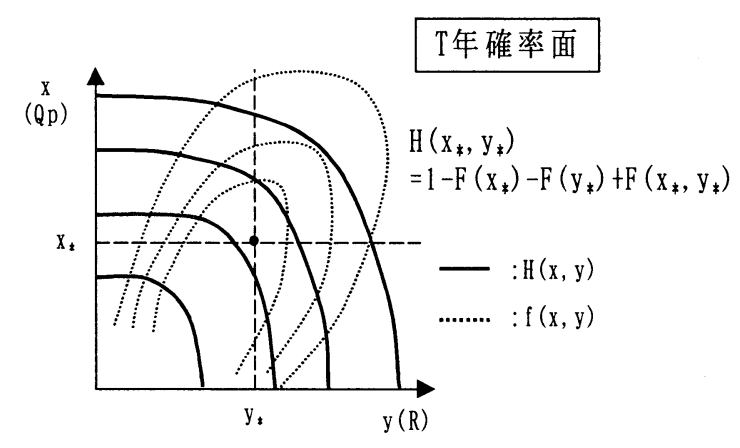

図-2 $\mathrm{T}$ 年確率面上の降雨量とピーク流量との関係

ここに, $\mathrm{x}$ は原水文量, $\mathrm{y}$ は正規変量, $\mathrm{k}, \mathrm{b}, \mathrm{c}$ は パラメータである。この分布の密度関数 $\mathrm{f}(\mathrm{x})$ は, 次式で表される。

$f(x)=\frac{1}{\sqrt{2 \pi}} \frac{\mathrm{k}}{\mathrm{c}} \exp \left\{-\left(\frac{\mathrm{y}}{\mathrm{k}}+\frac{\mathrm{y}^{2}}{2}\right)\right\}$

最尤解は, 尤度関数の自然対数を最大にするよう にパラメータ k, b, c を決めることであるから, 次 の非線形連立方程式を満たす $\mathrm{k}, \mathrm{b}, \mathrm{c}$ を求ればよい。

$\left\{\begin{array}{l}\frac{\partial \mathrm{L}}{\partial \mathrm{k}}=\frac{1}{\mathrm{k}}\left(\mathrm{N}-\sum \mathrm{y}_{\mathrm{i}}{ }^{2}\right)=0 \\ \frac{\partial \mathrm{L}}{\partial \mathrm{b}}=\frac{\mathrm{k}}{\mathrm{c}} \sum\left(\mathrm{y}_{\mathrm{i}}+\frac{1}{\mathrm{k}}\right) \exp \left(-\frac{\mathrm{y}_{\mathrm{i}}}{\mathrm{k}}\right)=0 \\ \frac{\partial \mathrm{L}}{\partial \mathrm{c}}=\frac{\mathrm{k}}{\mathrm{c}} \sum \mathrm{y}_{\mathrm{i}}=0\end{array}\right.$ 
（3）式を NEWTON-RAPHSON 法により解く方法 を述べる。

いま, 最尤解を $\mathrm{k}, \mathrm{b}, \mathrm{c}$ とし, 第 $\mathrm{j}$ 次近似值を $\mathrm{k} \mathrm{j}$, $\mathrm{b}_{\mathrm{j}}, \mathrm{c}_{\mathrm{j}}$,その差を $\triangle \mathrm{k}_{\mathrm{j}}, \triangle \mathrm{b}_{\mathrm{j}}, \Delta \mathrm{c}_{\mathrm{j}}$ とする。

$\mathrm{L}\left(\mathrm{k}_{\mathrm{j}}, \mathrm{b}_{\mathrm{j}}, \mathrm{c}_{\mathrm{j}}\right)=\mathrm{L}\left(\mathrm{k}-\triangle \mathrm{k}_{\mathrm{j}}, \mathrm{b}-\triangle \mathrm{b}_{\mathrm{j}}, \mathrm{c}-\triangle \mathrm{c}_{\mathrm{j}}\right)$ であるから， L( $\left.\mathrm{k}_{\mathrm{j}}, \mathrm{b}_{\mathrm{j}}, \mathrm{c}_{\mathrm{j}}\right)$ の $\mathrm{k}_{\mathrm{j}}, \mathrm{b}_{\mathrm{j}}, \mathrm{c}_{\mathrm{j}}$ に 関する偏微分をそれぞれ $\mathrm{k}, \mathrm{b}, \mathrm{c}$ のまわりにテーラ 一展開し, 二次の偏微分項までをとり, 若干の変形 をすれば，次式が得られる。

$$
\begin{aligned}
& \left(\Delta \mathrm{k}_{j}, \frac{\Delta \mathrm{b}_{j}}{\mathrm{c}_{j}}, \frac{\Delta \mathrm{c}_{j}}{\mathrm{c}_{j}}\right) \\
= & \left(\frac{\partial \mathrm{L}}{\partial \mathrm{k}}, \mathrm{c}_{j} \frac{\partial \mathrm{L}}{\partial \mathrm{b}}, \mathrm{c}_{j} \frac{\partial \mathrm{L}}{\partial \mathrm{c}}\right) \mathrm{A} / \mathrm{N}
\end{aligned}
$$

ここに, Aの行列要素 $a_{i j}(i=1,2,3, j=1,2,3)$ は それぞれ次式で示される。

$$
\left.\begin{array}{l}
\mathrm{a}_{11}=\frac{\left\{\mathrm{k}^{2}(\varepsilon+2)\right\}}{2 \varepsilon}, \quad \mathrm{a}_{22}=\frac{1}{\lambda^{2} \varepsilon} \\
\mathrm{a}_{33}=\frac{\varepsilon+\mathrm{k}^{2}}{\mathrm{k}^{2} \varepsilon}, \quad \mathrm{a}_{12}=\mathrm{a}_{21}=\frac{\mathrm{k}}{\lambda \varepsilon} \\
\mathrm{a}_{13}=\mathrm{a}_{31}=\frac{\mathrm{k}}{\varepsilon}, \quad \mathrm{a}_{23}=\mathrm{a}_{32}=\frac{1}{\lambda \varepsilon} \\
\lambda=\exp \left(\frac{1}{2 \mathrm{k}^{2}}\right), \quad \varepsilon=\left(1+\mathrm{k}^{2}\right)\left(\lambda^{2}-1\right)-1
\end{array}\right\}
$$

(5) 式の行列要素は大標本論的にはそれらの期待 值で置換でき, $\mathrm{E}[\mathbf{A}]^{-1}$ は最尤推定值の分散共分散行 列を表している。

結局，(4)，(5)式が繰り返し計算の基本式である。 なお，初期值については皘率解を利用すれば良い。

(1) 式より, $\mathrm{x}=\mathrm{c} \exp (\mathrm{y} / \mathrm{k})-\mathrm{b}$ であり, 特定の $\mathrm{y}$ の值に対して $\mathrm{x}$ の標準誤差 $S_{\mathrm{x}}$ は推定值 $\mathrm{k}, \mathrm{b}, \mathrm{c}$ の標 準誤差 $\delta{ }_{k}, \delta \delta_{b}, \delta$ 。の関数である。したがって, $\mathrm{x}$ の全微分を求めると，(6) 式が導かれる。

$$
\delta_{\mathrm{x}}=\mathrm{c}\left(\frac{\mathrm{dw}}{\mathrm{dk}}\right) \delta_{\mathrm{k}}-\delta_{\mathrm{b}}+\mathrm{w} \delta_{\mathrm{c}}
$$

ここに, $\quad \mathrm{w}=\exp (\mathrm{y} / \mathrm{k}), \mathrm{dw} / \mathrm{d} \mathrm{k}=-\mathrm{y} / \mathrm{k}^{2} \exp (\mathrm{y} / \mathrm{k})$

（6）式の両辺を二乗し，さらにその期待値をとれ ば，次式のような関係が与えられる。

$$
\begin{aligned}
& S_{x}{ }^{2}=\left\{\left(\frac{d w}{d k}\right)^{2} a_{11}+a_{22}+w^{2} a_{33}\right. \\
&\left.-2\left(\frac{d w}{d k}\right) a_{12}+2 w\left(\frac{d w}{d k}\right) a_{13}-2 w_{23}\right\}
\end{aligned}
$$

よって, 最尤推定值 $\mathrm{k}, \mathrm{b}, \mathrm{c}$ が求まれば，（7）式か ら特定の $\mathrm{y}$ 值（あるいはリターンピリオド $\mathrm{T}$ ）に対 する $\mathrm{x}$ の分散 $\mathrm{S}_{\mathrm{x}}{ }^{2}$ が計算できる。

そして, このときリターンピリオド $\mathrm{T}$ の変動域 $\mathrm{T}_{+}$ は, $\mathrm{F}(\mathrm{y})=\Phi(\mathrm{y})$ (ここに $\Phi()$ は標準正規分布) とす れば, $\mathrm{T}=1 /\{1-\Phi(\mathrm{y})\}$ であるから， $\mathrm{T}_{+}=1 /\left\{1-\Phi\left(\mathrm{y}_{+}\right)\right\}$と して計算できる。

\section{(2) 二変数同時生起確率}

本研究においては, 次のような二変数同時生起確 率を考える ${ }^{3)}$ 。

$$
\begin{aligned}
F(x, y)= & \int_{0}^{x} \int_{0}^{y} f(x, y) d x d y \\
= & F_{1}(x) F_{2}(y)+\frac{\rho_{x y}}{\sigma_{x} \sigma_{y}}\left\{\int_{0}^{x} x f_{1}(x) d x-\mu_{x} F_{1}(x)\right\} \\
& \cdot\left\{\int_{0}^{y} y f_{2}(y) d y-\mu_{y} F_{2}(y)\right\}
\end{aligned}
$$

ここで, $\mu_{\mathrm{x}}, \sigma_{\mathrm{x}}, \mu_{\mathrm{y}}, \sigma_{\mathrm{y}}$ はそれぞれ $\mathrm{x}, \mathrm{y} の$ 平均，標準偏差である。また， $\rho_{\mathrm{xy}}$ は $\mathrm{x}, \mathrm{y}$ 間の相 関係数である。(8) 式から条件付平均は次式で与え られる。

$$
\begin{aligned}
E(x \mid y) & =\int_{0}^{\infty} x f(x \mid y) d x \\
& =\int_{0}^{\infty} x_{1}(x)\left\{1+\rho_{x y} \frac{\left(x-\mu_{x}\right)\left(y-\mu_{y}\right)}{\sigma_{x} \sigma_{y}}\right\} \\
& =\mu_{x}+\rho_{x y} \frac{\sigma_{x}}{\sigma_{y}}\left(y-\mu_{y}\right)
\end{aligned}
$$

ここで $\mathrm{K}(\mathrm{y}) \equiv \rho_{x y} \cdot\left(\mathrm{y}-\mu_{y}\right) / \sigma_{y}$ とおくと

$$
\mathrm{E}(\mathrm{x} \mid \mathrm{y})=\mu_{\mathrm{x}}+\mathrm{K}(\mathrm{y}) \sigma_{\mathrm{x}}
$$

同様にして，条件付分散は， 


$$
\begin{aligned}
V(x \mid y) & =\int_{0}^{\infty} x^{2} f(x \mid y) d x-E(x \mid y)^{2} \\
& =V_{x}\left[1+\left\{C_{x}-K(y)\right\} K(y)\right]
\end{aligned}
$$

$\mathrm{V}(\mathrm{x}-\mathrm{y})>_{0}$ でなければならないから $\mathrm{K}(\mathrm{y})$ は,

$$
\frac{C_{x}}{2}-\sqrt{1+\frac{C_{x}^{2}}{4}}<K(y)<\frac{C_{x}}{2} \sqrt{1+\frac{C_{x}^{2}}{4}}
$$

これ以外の時, $\mathrm{V}(\mathrm{x}-\mathrm{y})=0.1$ とおく。ここに, $\mathrm{C} x$ は $\mathrm{x}$ のひずみ係数である。

\section{4. ケーススタディ}

\section{(1) 年最大流量の変動域}

年最大流量を発生させた降雨を対象に, 流出計算 から得られたピーク流量を標本として, 対数正規分 布による統計解析を行い, 変動域を求めた。流出計 算は，我が国の大河川において一般的に用いられて いる貯留関数を用いた。

図-3に，最尤推定值および各々のリターンピリ オド上での変動域士 $1 \sigma$ の流量値を結んだ線を描い た結果を示す。ただし，横軸は，流量を標準偏差で 無次元化した基準化変数で表示している。

リターンピリオド 100 年の確率流量は 5.1 となる が, $\pm 1 \sigma$ の変動域をみれば, 3.9 から 6.3 まで変 化し, 確率流量に対して $24 \%$ の変動の幅を有して いる。

\section{（2）降雨量の変動域}

降雨量に対して対数正規分布を用いて確率統計解 析を行い, 変動域を求めた。対数正規確率紙にプロ ットした結果を図-4に示す。流量の場合と同様に, 横軸は降雨量の基準化変数で示している。

リターンピリオド 100 年の確率降雨量は 6.2 であ る。実際の計画では, 6.2 を確率降雨量と定め, 対 象とする降雨波形の降雨量が 6.2 になるまで引き伸 ばす。土 1 бの変動域をみれば, 5.4 から 7.0 まで 変化し, 確率降雨量に対して $13 \%$ の変動幅を持っ ていることになる。

\section{（3）基本高水流量群の確率分布}

従来の計画では, 計画規模に対応する計画降雨量

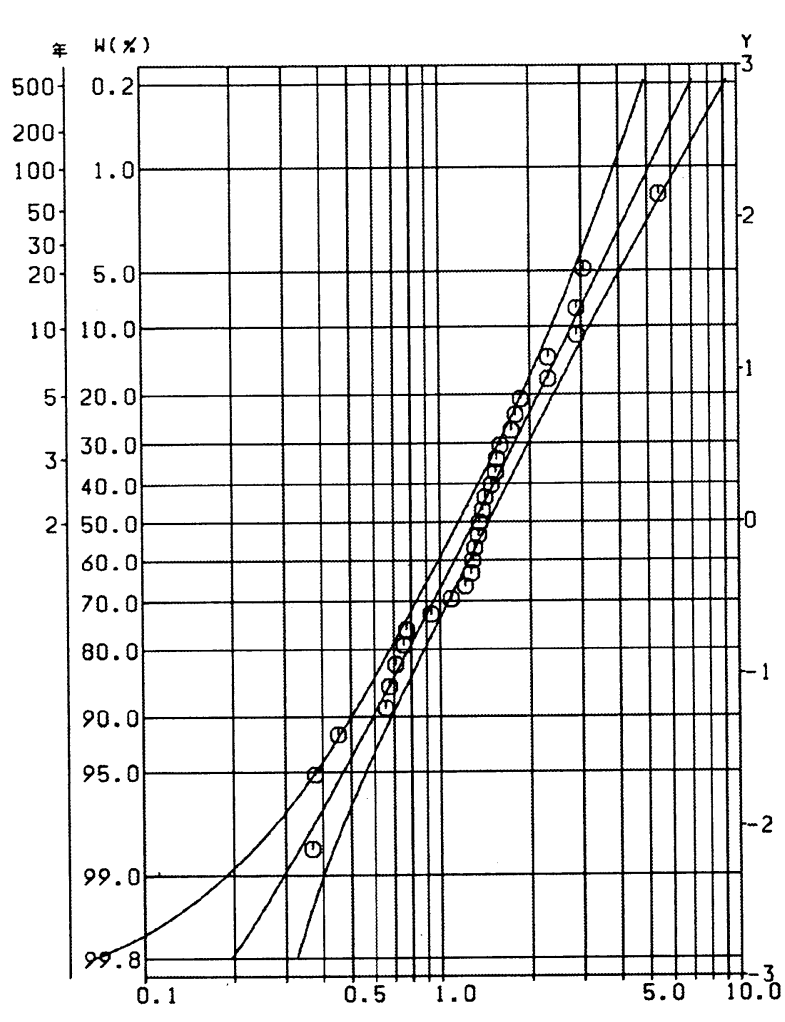

流量

図-3 年最大流量の変動域

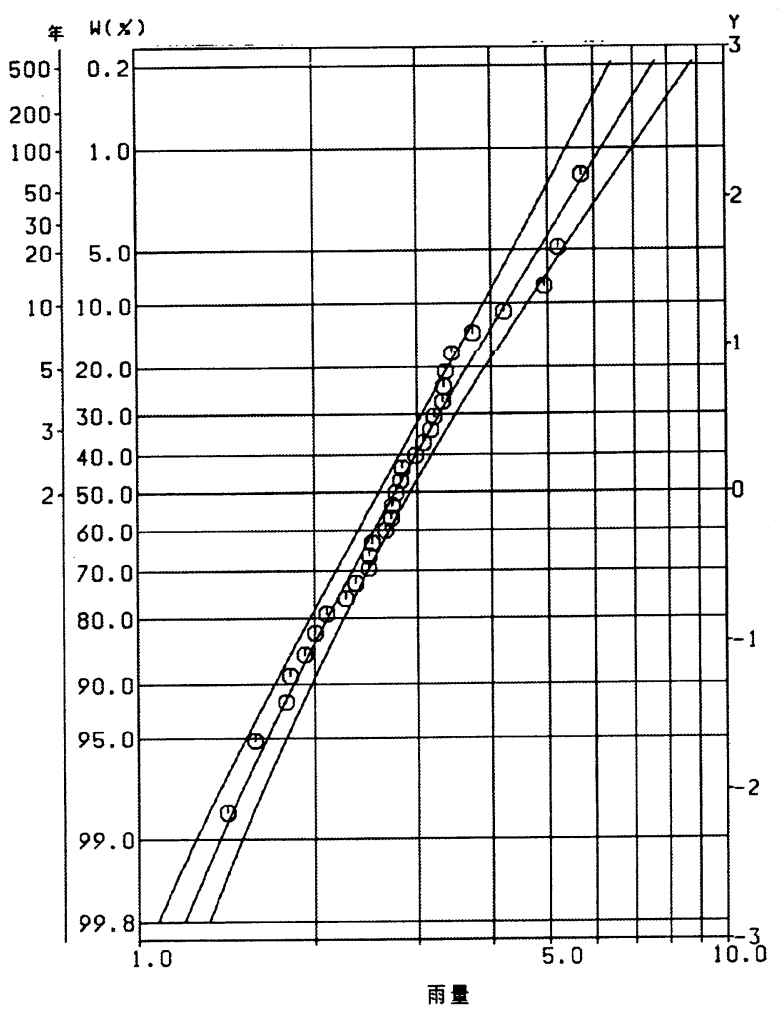

図-4 降雨量の変動域 
を確率統計解析により推定し, 選定した実績降雨波 形を計画降雨量まで引き伸ばす。この場合，選定し た降雨波形の時間分布, 空間分布がそれぞれ異なる ため, 流出解析によって求められた基本高水流量群 はばらつきを持つ。

そこで, 実績降雨の時空間分布の差異による基本 高水流量群の分布を調べるため, $\mathrm{T}=100$ 年の確率降 雨量を計画降雨量とした場合の基本高水流量群を算 定した。

図-5 は全ての降雨（96 洪水）から算定したピー ク流量の頻度分布である。同様に, 図-6 および図-7 は, それぞれ引き伸ばし倍率が 3 倍以下 (39 洪水), 2 倍以下の降雨（11 洪水）から算定したピーク流量 の頻度分布である。これらの頻度分布に適合する確 率分布形として，3母数ガンマ分布を採用した。

それぞれの図中で, 実線がガンマ分布の確率分布 関数であり, 点線が確率密度関数である。

これらのケースで同一の非超過確率（例として 70 \%) に対するピーク流量を求めた。実績降雨量が小 さい降雨波形は, 降雨倍率が大きくなる。このよう な降雨波形は, ピーク流量に支配的な短時間雨量も 大きくなり, リターンピリオドで評価すると数百年 にもなるような降雨波形となる。このため, 全資料 での分布は, 降雨倍率 3 倍以下の洪水や 2 倍以下の 洪水と比較して, ピーク流量の大きい部分における 頻度が高くなる傾向となる。

\section{（4）二変数確率理論による基本高水のピーク流量の \\ 信頼確率}

基本高水流量の信頼確率，すなわち，図-2 に示 した同時超過確率 $\mathrm{H}(\mathrm{x}, \mathrm{y})$ を求めるためには, 降雨 量の変動城を表す確率分布と基本高水流量群の確率 分布とを結合した分布を求める必要がある。そのた めには, (8) 式の基準化変量 $\mathrm{x}, \mathrm{y}$ の周辺分布とそれ らの間の相関係数を求めればよい。いま, $\mathrm{y}$ の周辺 分布は正規分布として, $\mathrm{x}$ の分布はガンマ分布とし て求められているから，降雨量とピーク流量との相 関関係を求めれば良い。

通常, 計画のリターンピリオドは, 既往最大洪水 のリターンピリオドよりも大きく設定される。この ため，図-1 および図-2 に示すような，計画規模に おける降雨量とピーク流量との相関係数を, 実績洪 水から推定することは不可能である。これを本研究 では，条件付き平均を与える(9) 式を利用して求め る。（9)式において $\mathrm{y}=\mu_{\mathrm{y}}+\sigma_{\mathrm{y}}$ とおけば,

$$
\mathrm{E}\left\{\mathrm{x} \mid \mu_{\mathrm{y}}+\sigma_{\mathrm{y}}\right\}=\mu_{\mathrm{x}}-\rho_{\mathrm{xy}} \sigma_{\mathrm{x}}
$$

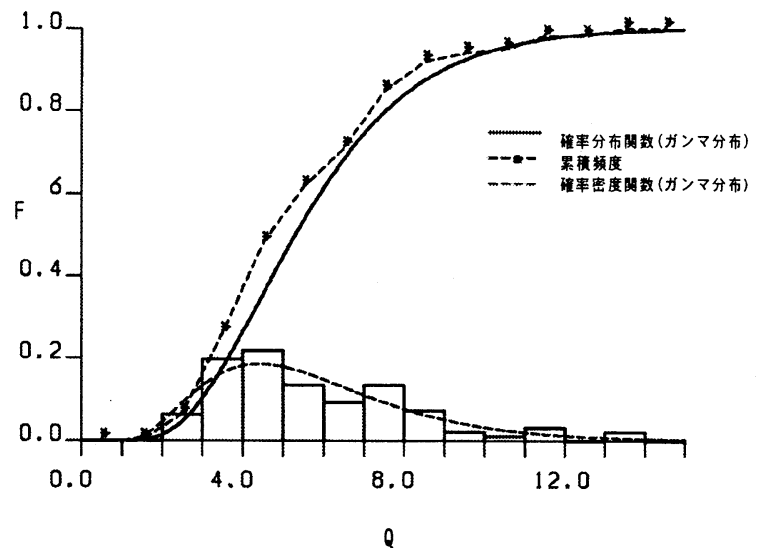

図-5＼cjkstart基本高水流量群の確率分布（全資料）

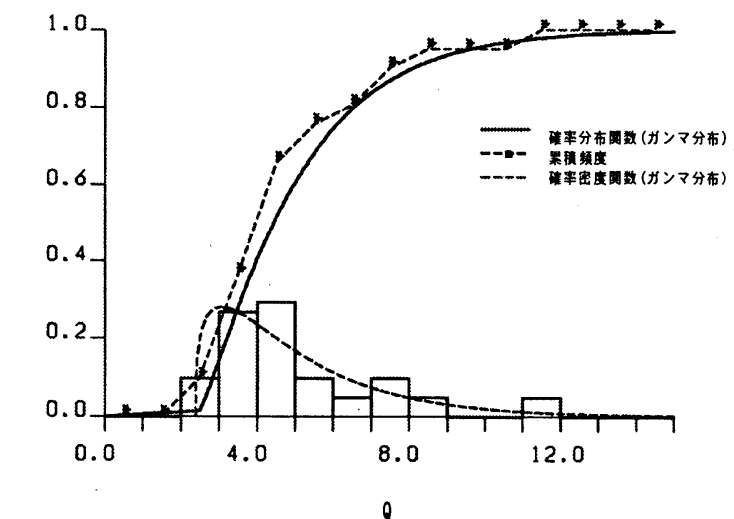

図-6 基本高水流量群の確率分布 (降雨倍率 3 倍以下)

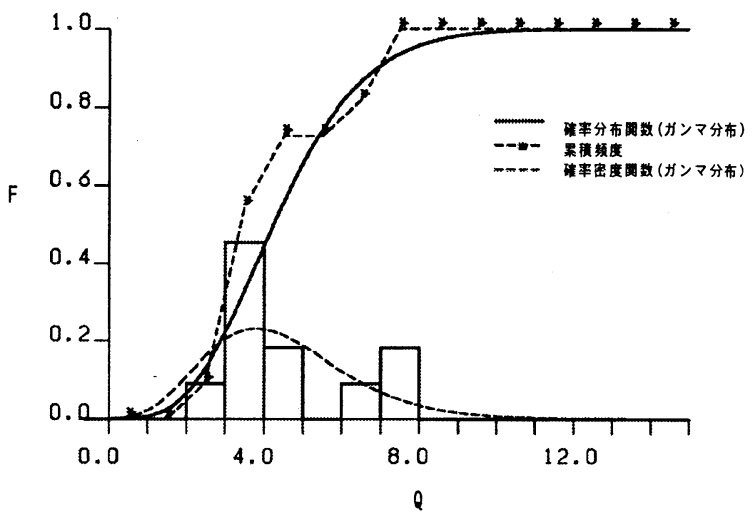

図-7 基本高水流量群の確率分布 (降雨倍率 2 倍以下)

従って，相関係数 $\rho_{\mathrm{xy}}$ は 


$$
\rho_{\mathrm{xy}}=\frac{\mathrm{E}\left\{\mathrm{X} \mid \mu_{\mathrm{y}}+\sigma_{\mathrm{y}}\right\}-\mu_{\mathrm{x}}}{\sigma_{\mathrm{x}}}
$$

となる。よって, $\mathrm{E}\left[\mathrm{x} \mid \mu,+\sigma y_{\mathrm{y}}\right]$ を推定し，

式に代入すれば相関係数が得られる。

ここで, $\mathrm{E}[\mathrm{x} \mid \mu,+\sigma$,$] の推定方法としては,$ 実際に生起した降雨波形パターンを用いて，実績降 雨量を $\mu_{y}+\sigma y$ に対応する值に変化させ, 流出解析 により得られるピーク流量群の平均とする方法を取 つた。対象とする降雨波形パターンとしては，相関 をとる際の資料数がある程度必要であるということ と, 降雨倍率が大きい降雨波形では，波形にひずみ ができる場合があることから，計画降雨量に対する 引き伸ばし倍率が 3 倍以下の降雨を選定した。この 結果, (17) 式から相関係数を推定すると $\rho_{x y}=0.385$ を得た。

さらに，降雨量の変動域を表す確率分布と基本高 水流量群の確率分布との二変数同時生起確率分布を 求めた。図-8 に, $\mathrm{T}=100$ 年確率規模に対する等同時 超過確率曲線と, 等同時確率密度曲線を示す。図中 の実線が等同時超過確率曲線を，点線が等同時密度 曲線を表している。

$\mathrm{T}=100$ 年の確率規模に対して, 降雨量の最尤推定 値は 4. (2)に示したように， 6.2 となる。従来の方法 によると，この值が計画降雨量として採用される。 次に, 実績降雨を計画降雨量になるように引き伸ば し, 流出解析により基本高水流量群を算定する。そ の後, 設定したカバー率に対応する值を基本高水流 量とする。本研究では, 図-6 に示す, 降雨倍率 3 倍以下の洪水波形から得られた基本高水流量群の非 超過確率 70\%に対応する值 5.6 を基本高水流量と設 定する。

図-8 において, $\mathrm{y}=6.2, \mathrm{x}=5.6$ 上の超過確率は, $\mathrm{H}(\mathrm{x}, \mathrm{y})=0.25$ となる。これは, $\mathrm{T}=100$ 年規模に対 して平均的に最も生起する降雨量 6.2 と基本高水流 量 5.6 を同時に超過する洪水となる可能性が，4 回 に 1 回は起こり得るということを示している。

\section{5.おわりに}

降雨量が計画規模に対応するリターンピリオドを 持つように定められた基本高水流量は，数種類の降 雨波形を用いた流出解析結果からカバー率の検討を 行われた後，定められている。このため，計画の基 本量となる基本高水流量の超過確率が，計画の目標 とする治水安全度に対応する確率と一致しているか 不明である。

本研究では, 治水安全度を持つ降雨量が生起した

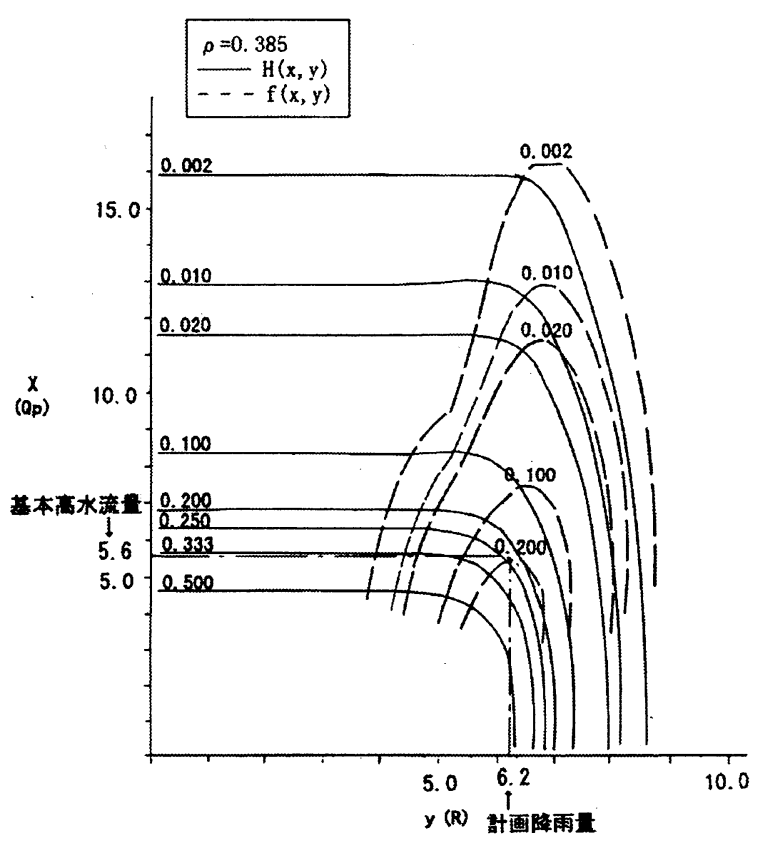

図-8 $\quad \mathrm{T}=100$ 年確率規模に対する 基本高水流量の信頼確率

ときの基本高水流量と, 降雨量の生起確率との差異 を二変数確率理論により評価した。

この結果, $\mathrm{T}=100$ 年の確率降雨量と基本高水流量 5.6 の同時超過確率は 0.25 と推定された。これは, 4 回に 1 回は計画降雨量と基本高水流量を同時に超過 する洪水となる可能性があることを示している。

\section{参考文献}

1)建設省河川局監修，（社）日本河川協会編， 改訂新版 建設省河川砂防技術基準(案) 同解説 計画編, pp.9 11

2) 端野道夫 : 最尤法による対数正規分布の実用的定 数推定法とその応用例, 土木学会水理講演会 論文集, Vol.20，pp.29～34，1976

3)端野道夫, 金光泰秀, 西田佳生, 西岡昌秋: 多峰降雨モデルによる計画高水の決定法 (続報), 水文・水資源学会研究発表会要旨集, pp.276 279, 1992

（1998. 9. 30受付） 